\title{
Teaching performance of faculty of medical specialties, with and without teacher training, of the Puebla delegation, of the cycle 2017
}

\section{Summary}

Teaching performance of faculty of medical specialties, with and without teacher training, of the Puebla Delegation, of the 2017 cycle.

Background: eldd ERFORMANCE centre active formation process within the formal education system, $p$ or what your analysis and evaluation in a concrete and representative way, it is important.

General objective: To evaluate the teaching performance of the teaching staff of medical specialties, with and without teacher training, through the resident doctors of the Puebla Delegation, in the academic year 2017.

Material and methods: Study observational, transversal, descriptive or, comparative. $\mathrm{S}$ and evaluate teacher performance in two groups of medical residency teachers, teachers with teacher training and untrained teachers to be evaluated by students, resident physicians enrolled in the academic year 2017, who answered a questionnaire prepared on purpose.

Results: Accordance with the obtained by questionnaire.

Conclusion: Defender of the results and have made the discussion of the contrast with other and background out researches.

Keywords: medical education, ERFORMANCE teaching, training teachers, evaluation.
Volume 2 Issue 6 - 2018

\author{
María Urbelina Fernández Vázquez \\ Full-time professor at the Teacher Education and Training \\ Research Center Registration, Mexico
}

\begin{abstract}
Correspondence: María Urbelina Fernández Vázquez, Family Doctor, Full-time professor at the Teacher Education and Training Research Center Registration 1017090।, Tel 22254I7762, Email maryurbefer@gmail.com
\end{abstract}

Received: September 12, 2018 | Published: December 28, 2018

\section{Theoretical framework}

Evaluation teacher performance means assessing compliance with the functions and commitments of the teacher, as well as the performance of the achievements obtained during a certain time. The evaluate teacher performance is to assess the performance of their responsibilities in señanza-learning and improvement of their students. Nowadays, the professionalization of all teachers is fundamental since the role of the teacher remains elementary in terms of the quality and relevance of education, and not falling behind becomes an indispensable strategy to be on par with what the world demands. ${ }^{1}$

\section{The evaluation of teacher performance}

The evaluation of teachers in our context tries to give it its formative sense, to procure a conscious process, on aspects such as the difficulty of "installing a universalized system of evaluation of education", both for teaching and learning, as well as for teaching performance. In addition, there is evidence of the precariousness and lack of functionality that the different legal aspects that normalize evaluation have had from educational policies, arising from international organizations that are unaware of the realities of our school and social contexts. The teacher evaluation is used for different purposes in organizations and affects decision-making, can be used as $b$ ase to identify and 1 educational, com or are the powers phenomenon. Assess such elements is essential and, intentionally and periodic. ${ }^{2}$ In this sense, the evaluation of the teaching performance should not generate in the teachers, feelings of fear or rejection. Nor should it have as objective to monitor or control, but to favour the improvement of the teaching staff through the identification of those qualities that make up a good teacher.

The evaluation as a form of control, exclusion, monitoring, is denatured and unacceptable, as it disfigures the professionalization, training and performance of teachers. For this reason, it is necessary an evaluation system that is more fair and rational and that allows to evaluate the performance of the teacher with objectivity, depth and impartiality. ${ }^{3}$ The teacher needs, in the first place, to have knowledge and to master his subject to "teach" as much in the "know" as in the "know how"; that is, in addition to theoretical knowledge, it requires experience in the workplace (general culture, professional training). Must have pedagogical skills and the ability to transmit their knowledge (good communication, motivation, interest, organization, clarity, responsibility, compliance, consistency), complementing this ability with the presence of attitudes and values (justice, assistance, punctuality, respect, demand, honesty) to promote learning processes in the students. Likewise, it is necessary to have the qualities of intelligence, creativity, innovation, wisdom, empathy, openness to experience and charisma. ${ }^{4}$

Santos, ${ }^{5}$ mentions five reasons why evaluations should be carried out at a higher level: 1) rationality, 2) responsibility, 3) professionalism, 4) collegiality and 5) perfectibility; In addition, the evaluation must be done, taking into account the following considerations:

a) It is attentive to processes and not only to results.

b) It gives voice to the participants in conditions of freedom. 
c) It uses diverse and sensitive methods to explore reality.

d) It is aimed at improving the university and, through it, society.

e) Take into account the values from his own example as a teacher flexible, curious, enterprising, creative, independent, tolerant, cooperative, responsible, transparent, and enthusiastic.

f) It is holistic.

g) No $t$ i Jan the privilege of $\operatorname{truth}^{5}$

\section{Specific background}

The training of medical specialists deserves more dedication, on the part of teachers is a fundamental challenge, hence the importance of having competent teachers if we want a quality education. In order to improve the teaching activity of the medical professor, it is essential to evaluate their performance as a form of accountability on their teaching performance and thus to give a feedback staff, providing you contrasted evidences about his practice, which could be useful, to receive a feedback on his teaching performance and thus facilitate the introduction of changes for improvement. ${ }^{6}$ The teaching activity must be in continuous revitalization, strengthen the culture of the evaluation, give information about the formative quality. $\mathrm{P}$ or what some research studies mentioned $\mathrm{r}$ to $\mathrm{n}$ in order to theoretically support and teacher performance value ation. ${ }^{6-8}$ The extra Materan in 1999, referred to by Estrada, He conducted a research at No. 1 School District Venezuela Yaracuy State, assessed and 1 process of academic supervision over the managerial staff for the improvement of the teaching performance of the professors of the classroom. She noted that the supervision $\mathrm{p}$ or part of managers was inadequate, so must change if a positive transformation in the quality of educational processes ${ }^{9}$ is expected. The Mexican Institute of Social Security (IMSS), recognized as a leading institution in the field of social security, is also an obligatory reference in the process of training personnel for health and in the field of continuing education and updating of its personnel assigned to the health care of approximately half of the population of Mexico, as well as in the high-level training of their executives in the medical area, in the generation, dissemination and use of scientific knowledge and in the training of teaching staff in the area of health. S part of the health sector, the IMSS has assigned various functions have been concretized in the model of atening to health is what following: take actions to increase the level of health, reduce risks and prevent damage to health, provide comprehensive medical care, train, train and develop staff for health care and real izar medical research. ${ }^{10}$

At the Autonomous University of Baja California, an investigation was conducted on the validation of a Questionnaire on the Evaluation of Teaching Competence through a rigorous methodological process of accumulation of evidence of validity and reliability. The questionnaire is based on the Teacher Competencies Evaluation Model (MECD). The one-dimensionality analyzes $(n=128,791)$ and $\operatorname{AFE}(n=67,111)$ were replicated, 32 reagents were evaluated to evaluate the same construct, the internal structure revealed two factors: planning and management of the teaching-learning process and, conducting and evaluating the Teaching learning process; a total variance of $75.02 \%$ and Cronbach's alpha of 0.98 . The structure was checked with modeling of structural equations $(\mathrm{n}=462)$, where an RMSEA $=0.07$, SRMR $=0.02$, CFI and $\mathrm{TLI}=93$ resulted. It is concluded that the questionnaire integrates the components of the teaching competence that are significant for the students and demonstrates its representativeness with the dimensions of the MECD. ${ }^{11}$ Valdez, referred to by Tejedor. ${ }^{12}$ It affirms that the evaluation of the teaching performance is "an activity of analysis, commitment and formation of the teaching staff, that values and judges the conception, practice, projection and development of the activity and of the professionalization teacher". The evaluation, whether you like it or not, guides the educational activity and determines the behaviour of the subjects, not only because of the results it can offer, but also because it pre-establishes what is desirable, what is valuable, what it should be. Teacher evaluation formance must then be conceived as a process, training and summative or at the same time, the construction of knowledge based on actual teaching performance, with the aim of provoking changes in them, from the axiological consideration of the desirable, the valuable and the must be of the teaching performance. This type of evaluation is based on the suitability, ethical and pedagogical, requiring pestation of educational services and takes into account the knowledge, skills, attitudes and values $\mathrm{s}$, which are evident in the socio- economic contexts of COUNTRY. ${ }^{12}$

In 2013, a study was carried out at the University of Nariño, Spain, where the teacher's performance is evaluated by competences, where the results of the impact analysis of the pedagogical performance evaluation processes of the teachers of the University of Nariño are shown. Research carried out with a sample of 580 informants: executives, teachers and students from the Pasto headquarters and Ipiales, Tumaco and Túquerres subsedes; Through semistructured surveys, the evaluative-descriptive-proactive study explores the assessment and discourse of the informants using a methodical examination on the derivations of the evaluation of the teaching performance, whose findings are triangulated with the results of the systematic reflection around the theoretical realities related to the question of inquiry and, the synthesis documentary material is produced that culminates with an alternative proposal as an Improvement Plan. ${ }^{13}$ Sánchez Ochoa ${ }^{14}$ develops a bulleting instrument to evaluate teacher performance where he mentions that educational institutions face the challenge of selecting their teachers for the best performance of their functions, as well as training them by exploiting the human potential that each teacher has. However, it is difficult to differentiate the outstanding teachers in their competences and aptitudes from those who only transmit knowledge. Based on the identification and differentiation of skills and aptitudes of good versus talented teachers from a previous study by Sánchez \& Domínguez, ${ }^{14}$ they developed an instrument to assess aptitudes and teaching skills of 10 vignettes that staged different situations of their practice that the teachers had to solve. The instrument proved useful in detecting the strengths and weaknesses of teachers in relation to the characteristics that were evaluated, as well as adequate to measure unusual aspects within institutionalized valuations. ${ }^{14}$

In another study conducted at the Hospital Dr. Manuel Gea Gonzále $z^{15}$ to evaluate the different degrees of teaching performance according to the opinion of the residents, where the study population was constituted by the professors of the aforementioned hospital. Whose variables considered were age, gender, year of residency and specialties classified in Medical and Surgical. The anonymous questionnaire of teacher performance evaluation by the resident's opinion has evidence of validity and reliability; composed of 37 statements and five dimensions with a Likert-type response scale. The results obtained where 25 professors of 13 specialties were evaluated by 281 residents who thought that the teaching performance is acceptable, with an average of 4.25 for the medical specialties and excellent with an average of 4.70 for the surgical ones. The best valued dimension was knowledge of the subject with an average of 4.32 in 
contrast to the evaluation dimension with 3.84. It should be noted that the scores of the surgical specialties were statistically higher in four of the five dimensions compared to the medical ones, with the exception of dimension I, which refers to the teacher-resident relationship and motivation.

\section{Conclusion}

The academic floor of the hospital was valued by the opinion of the residents as acceptable. They found diverse degrees of teaching performance that ranged from sufficient to acceptable to excellent. Surgical specializations were better evaluated compared to medical ones. ${ }^{15}$ The education system depends on the quality and performance of its teachers, so continuous improvement processes must be carried out. For what is carried out a study in the UNAM in 2011 to evaluate the teaching performance of the professors of Public Health I of the Faculty of Medicine of the National Autonomous University of Mexico through three strategies. The evaluation was carried out under a meditational model through three strategies: student opinion, selfassessment and academic achievement of the students. Descriptive statistics, Student's t test, Anova and Pearson correlation were applied. Their results were the following: 20 teachers of Public Health I were evaluated, which represents $57 \%$ of the total that the subject imparts. The performance of the teacher by self-evaluation was rated high in comparison with the student's opinion; it was confirmed with the statistical analysis that the difference was significant.

The difference between the three evaluation strategies became more evident between the self-assessment and the score obtained by the students in their academic performance. In conclusion, he mentions that the integration of the three strategies gives us a more complete vision of the quality of teaching performance. Apparently, the strategy of academic achievement has a greater objectivity compared to the opinion of the students and the self-evaluation. ${ }^{16}$ A study was conducted in the south central region of the state of Chihuahua, in the Education Sector 25, composed of five school zones that provide their services to the municipalities of Meoqui, Julimes and Delicias, which was developed during the 2013-2014 school years. 2014-2015. The study is mixed-cut, sequential comprehensive-correlational procedure. The first phase of the study was developed in Education Sector 25, with a sample of 135 subjects. To collect qualitative information, self-administered questionnaires were applied, both with open and closed questions, as well as in-depth interviews. The second phase was directed by a quantitative approach, the population to whom this study was applied were the teachers who work in front of a group in the School Zone 121, made up of 42 teachers, information was collected from the participants, video recordings of a day were made Teachers' school, in addition to analyzing their didactic plans, as well as the assessment instruments they use, which was assessed through a checklist designed exprofessional to assess the teaching performance. The results were: there is a correlation of 0.578 between the years of service of the teacher and the score assigned to their students in the teaching career; there is no association between the teaching performance and the context where one works; there is no relationship between teacher performance and school performance of students on standardized tests. $2.4 \%$ of the representative sample presented an excellent teaching performance, $7.3 \%$ a poor teaching performance. $39 \%$ of the teachers observed are located with a good teaching performance ${ }^{17}$ Pimienta Prieto in 2014 carries out a study in a private institution in the metropolitan area of Mexico where it presents the process of design, construction and validation of a questionnaire to evaluate the academic performance of university professors from the perspective of the students. The process includes the specification table that operationalizes the construct; It has served as a reference both for the construction of the statements of the scale, as well as for the assessment by experts of the coherence between the questions and the specifications (content validity). The questionnaire was applied to a random sample of students (440) from a private institution in the metropolitan area of Mexico. Reliability has been determined as internal consistency and partition by halves; in addition, an exploratory and confirmatory factorial analysis to determine the adequate measurement of the construct that is intended to be evaluated. The results have shown a reliability of 0.965 (Cronbach's alpha), the degree of agreement, with Cohen's kappa index, has been considered as greater than 0.7 and the confirmatory factor analysis points to two factors of three that were held; without departing drastically from the theory that served as the basis. ${ }^{18}$ Nava \& Rueda ${ }^{19}$ analyzes the evaluation of teacher performance as a topic on the public agenda and points out the role played by the media in this regard. It proposes to incorporate into the discussion elements contributed from the experiences in the field of research, in order to approach the subject in a documented and analytical manner. Considering the disparities in the educational landscape, it is pointed out the need to provide the teacher with the indispensable conditions for their adequate performance, as a prerequisite to evaluation. For the design and interpretation of results, the evaluation must consider the diversity of profiles, institutional, sociocultural and economic contexts in which teaching is carried out. The research highlights some aspects to consider in order guiding the design of policies and actions in favor of improvement of performance and teacher evaluation. ${ }^{19}$ Martínez González ${ }^{15}$ validates an instrument to evaluate the teaching performance in medical specialization courses within IMSS. Where content validity was sought through the review of documents, the opinion of experts and medical students of various specialties. The construct validity was estimated with an exploratory factor analysis, keeping the loading questions $\geq 0.50$ and classified in a single factor; Cronbach's alpha coefficient was calculated.

\section{Results}

157 residents evaluated nine professors. A response rate of $75.1 \%$ was obtained. The questionnaire was constituted by 37 questions. We identified five factors with eigen values $\geq 1$ that together explained $52.5 \%$ of the total variance. Cronbach's alpha coefficient was 0.9596 for the questionnaire. Conclusions: the questionnaire reached high reliability and can be used to evaluate the teaching performance within the medical specialties. ${ }^{20}$ Valle and cols in 2004 design a questionnaire for students to evaluate the teaching skills of the teacher, according to the definition of the teaching qualities of the basic medical sciences, and to identify the underlying dimensions. All this with the purpose of carrying out an evaluation of the teaching of basic medical sciences in the Faculty of Medicine of the National Autonomous University of Mexico (UNAM), as part of the evaluation project of teaching in that institution. Material and methods: 6239 students answered 6598 questionnaires that evaluated 327 teachers. The questionnaire was applied during normal classes in the 1995-1996 school year. The teachers evaluated were not present at the time the evaluation was carried out. Results: three factors were defined that according to their content were called teaching strategies, evaluation of learning and ethics and responsibility. Conclusions: some similarities were found between the content of the questionnaire items and those used in other instruments; however, this questionnaire also includes skills and abilities that the teacher must teach to the students in order to achieve 
the profile established in the curriculum. of the Faculty of Medicine of the National Autonomous University of Mexico. ${ }^{21}$ Reyes Piñuela conducts a study in order to conduct an evaluation of the teaching competence, report the results of reliability analysis and validity of the Teacher Competency Evaluation Questionnaire based on the opinion of the students, in a population of university students Mexicans The theoretical structure of the questionnaire corresponds to the Teacher Competency Evaluation Model and is a scale with 35 Likert-type items with five response levels. A one-dimensionality analysis of the test was performed with a sample of 128,791, an Exploratory Factor Analysis (AFE) with 66,148 data and a Confirmatory Factor Analysis (CFA) with 462 data. The results of the unidimensionality analysis with the Rasch model showed that 32 reagents evaluate the same latent trait; in the AFE a bifactorial structure was obtained, planning and management of the teaching-learning process, and conduction and assessment of the teaching-learning process, both factors explain the $75.02 \%$ variance and a Cronbach's alpha of 0.98 ; in the AFC the values of goodness-of-fit indices were RMSEA $=.07, \mathrm{CFI}=.93$, and SRMR $=0.02$ the structure of the model to which the data were adjusted in an acceptable manner was made up of two factors with 25 congruent reagents with the underlying model. ${ }^{22}$

Ramírez Munguía ${ }^{23}$ and collaborators carried out a study whose objective was to evaluate the scope of the visit of professors in the development of a position of education and aptitude for the criticism of texts in education, in a teacher training program. Material and methods: a group of 10 teachers participated. The development of a position on education and skills for the criticism of texts in education and research reports was evaluated through three previously validated instruments. With the following results: after the course, the participants increased their scores. With the Wilcoxon test, $\mathrm{p}=0.005$ was obtained in the three instruments applied. All the participants showed in the retest a position on education. Whose conclusions: the educational strategy modified and increased the position of teachers towards education. Although incipient, the results point to a significant change of aptitudes for criticism, which should be encouraged with continuous training through the Institutional Teaching Career. ${ }^{23}$ Márquez \& Madueño ${ }^{24}$ Realize an instrument to evaluate the psychometric properties to support the evaluation process of the university teacher. Given the importance of reflecting on the teaching praxis, the evaluation of performance continues as one of the resources to ensure the quality of education. The objective of this study was to identify the psychometric properties of the instrument applied to students of a University of Sonora in order to recover their opinion on the basic competences of the teacher in the delivery of undergraduate courses, and thus contribute to the decision making in the teacher evaluation process. From the 30,224 questionnaires answered, a factorial analysis (construct validity) was carried out using the principal components method, extracting two factors that explain $73.1 \%$ of the total variance; He highlighted the lack of definition of 3 items. An alpha of 0.97 (internal consistency) was calculated. Although the results show that the instrument is valid and reliable, it is recommended to analyze in depth the content validity and consider strengthening it for its application. ${ }^{24}$

\section{Justification}

So far, the teaching performance of graduates of the Teacher Professionalization Diploma for Health Education, trained at the Center for Educational Research and Teacher Training (CIEFD) of the State Delegation of the IMSS in Puebla. S and comes to personal health seconded health care units of the three levels of care, who participates in different educational processes 1 IMSS Delegation of Puebla. These teachers are responsible for the formative processes of resident physicians of different specialties, why and the importance of evaluating them, and which will produce vali elements bears to promote and ensure greater quality, efficiency, performance and relevance of teaching actions, with the primary idea of better results of educational processes. It would also allow recognition of teacher performance, identify their strengths and weaknesses. Even support the teacher who starts his education in the field of education and improve their professional skills is. It is necessary to support teachers, assess and recognize their work through a system that allows identifying their effort and good performance, thus contributing to the impetus for their professional development and co-responsibility in educational changes. E s important to know the teaching practice that serves as an element proactive generator shafts for reflection and discussion on this subject, so to improve teacher training conducted at the Centres for Educational Research in Education and Teacher Training of IMSS, particularly located in the city of Puebla, Puebla. That is why this paper will present the importance of the professionalization of Centres do and its impact on teacher performance to improve educational quality.

\section{Problem statement}

Despite the teacher training through the Diploma of Teaching Professionalization for Health Education in the IMSS and having a significant number of teachers graduated, it is external by authorities of the Puebla Delegation, a lack of quality of the processes education related to the training of the next specialist doctors. The educational actions in health of the IMSS, training, continuing education and training of the personnel that attends the processes of health, illness and rehabilitation of the right holders and their families, are in charge of the same health personnel assigned to the services. While these people know their profession, it is not enough for them to perform satisfactorily as an educator. Being able to determine whether the teaching performance of graduates professors Dsdiplomado it has an impact on the teacher's education and, in turn, the teacher's actions favour the learning of the students under the principles of the Institutional Educational Model, with an approach based on professional competences, can you guide and provide feedback if the trained teachers meet the expected performance standards. According to This approach, in order to increase the quality and equity levels of the educational quality in health of the IMSS, is fundamental, not only to optimize the initial and permanent training systems for the professors of medical specialties, but also to ensure that the teaching profession is an attractive work activity. There is a need to carry out an evaluation of the teaching performance that trains the next specialists, that is valid, with a purpose and with ethics, it must be an analysis process that allows assess their practice $\mathrm{s}$, if they already have teacher training through the Diploma is expected a better performance of the graduates (as). The evaluation of the teaching performance will be carried out through a validated instrument. This will be used to identify clinical teaching skills, provide a reliable confiretroalimentation and relevant information on the strengths and weak-Dades teachers.

Until now, the most used means to evaluate teaching has been the opinion questionnaire of the students, who are considered as a source of information on their performance, since students are the ones who interact constantly with the teacher and those who perceive whether or not you have pedagogical skills to transmit your knowledge, if you 
have an adequate and real schedule of your course, if you communicate efficiently. ${ }^{25}$ To evaluate the performance of a person means to evaluate the fulfilment of their functions and responsibilities, as well as the performance of the obtained achievements, in accordance with the position that is exercised during a determined time. Evaluating the performance of the teacher, is a process through which seeks to make judgments on the fulfilment of their responsibilities in teachinglearning and development of their students, after monitoring their actions, progress made with students, development of his work area and actions directed in his academic unit. This evaluation is related to suitability, ethics and pedagogy. Also can be evaluated by other teachers who are experts in teaching, the advantage is that it would be more objective evaluation, the disadvantage is that the observation of at least two teaching that evaluate to $\mathrm{n}$ to teacher at different times, try that achieves a agreement among inter-observers.

Within the context of medical education, there is little research regarding teacher performance in specialization medical ions and if this is higher quality to be professionalized, which has conditioned, lack of recognition and perfection of the labour teacher. Analyzing the advantages and disadvantages of evaluating teaching performance through observation by different people, this study opts for the evaluation of the performance of the students as a first moment since this study will continue in a second moment with the formulation of an instrument for the evaluation of performance by teachers through the eyes of two teaching experts. From the above, the following research question derives. How is the teaching performance of teachers of medical specialties, with and without teacher training, according to their students, of the Puebla Delegation, in 2016 ?

\section{Hypothesis}

It is assumed that the teachers trained through the Diploma of Teaching Professionalization for Health Education in the CIEFD Puebla, from 2010 to 2015, have a higher teaching performance than teachers who do not have teacher training.

\section{Goals}

General Objective: To evaluate the teaching performance of the faculty of medical specialties, with and without teacher training, through their students, of the Puebla Delegation, in the academic year 2017.

\section{Specific objectives}

Elaborate and validate an instrument to evaluate the teaching performance directed to its students.

Determine who has better performance, trained teachers or those who do not.

Identify the main problems that students glimpse about the performance of their teachers.

\section{Material and methods}

\section{Type of study}

Prospective, observational, transverse, descriptive, comparative

\section{Study population}

Teaching staff of the medical specialty courses of the State Delegation of the IMSS in Puebla.

\section{Inclusion criteria}

Active teachers of medical specialties, with appointment of head, assistant or assistant, trained through the Diploma of Teaching Professionalization for Health Education from 2010 to 2015, in the Center for Educational Research and Teacher Training and attached to the State Delegation of the IMSS in Puebla. Active teachers of medical specialties without any training for teaching practice and assigned to the State Delegation of the IMSS in Puebla, with appointment of head, deputy or assistant.

\section{Exclusion criteria}

\section{Any}

\section{Elimination criteria}

They are discarded questionnaires that are not answered entirely by students.

\section{Type of sampling}

Non-probabilistic sampling method.

\section{Sample size}

Census faculty specialization courses Medic be sought to the Delegation State of the IMSS in Puebla, whose No. ero reported is 100.

\section{Study variables \\ Conceptual definitions \\ Teaching performance}

Teaching performance is one of the variables to understand the quality of the pedagogical exercise of teachers. In the field of medical residencies, there are no criteria specifying what should be the specific functions and roles of the teacher in this study is defined as: teacher performance to a CTION of 1 teacher medico has the responsibility to train doctors a medical specialty course at the IMSS. Responsibility that demands to fulfil the activities or tasks programmed in his role as teacher; to devote his teaching activity to the educational policies in health matters of our days; to plan the teaching activity; to dominate the updated disciplinary contents that it teaches; facilitate learning; foster an environment for collaborative work; c) discover and understand the characteristics of the doctors in training and their contexts; $s$ an example to the group of doctors in training regarding professional, ethical and human behaviour that provides existential meaning to life; to evaluate the own performance and the learning of the doctors in formation, with a view to improving the educational process.

\section{Teacher training}

Formal educational process aimed at populations that have teaching responsibilities, whose duration varies. Initially, these are introductory or basic courses for teaching practice, diploma-type. According to the needs of the teachers, the training can continue with other types such as specialization courses. Even this training can demand the accreditation of a postgraduate degree in education. The theoretical-methodological approaches of these different courses are also diverse, although in the present there is a tendency towards constructivism, cognitiveism, the development of professional competences and the application of information and communication 
technologies in education. This training aims at an ideal performance of the teacher before the students, for which it must learn theoretical aspects of education, educational methodology, evaluation of the educational process, etc., in a few words the professionalization of the teacher is intended. In IMSS this professionalization has been sought through the implementation of the Diplomat of Professionalization for Education in Health Education. Como has occurred at the Center for Educational Research and Teacher Education, the Delegation State of the IMSS in Puebla, from the year 2010 to 2015.

\section{Indicators of performance teaching}

\section{General aspects of teaching practice}

Social activity exercised by a teacher or teacher when teaching. the aspect of the personal care of the teacher, compliance with scheduled times, attendance at scheduled sessions, publicizing the program, respectful respect to residents.

\section{Development of class}

Organization of the activities that are given during a class, to be able to achieve a learning in the students, as effective as possible.

\section{New technologies communication}

Of being only language to become gradually in mass media and cultural mediation. In modern times, communicating means putting in common with others, ideas, thoughts, through different channels and with a shared code. As teachers or trainers of people, we have the obligation to transmit our students skills, attitudes and values to make them competent in certain areas of knowledge. In this process, the new communication technologies take on special relevance.

\section{Attitude of the teacher}

Motivator, integrator, innovator, creative, critical, but above all exercise authority based on knowledge and closeness. In continuous improvement. Horizontal and non-vertical authority, understanding that learning is collaborative, participatory, where the teacher stops being the centre of learning "(Momberg, referred by Salas 2012).

\section{Evaluation}

Employ a varied range of evaluation strategies, which allow you to obtain evidence of the performance of the skills developed in the students.

\section{Operational definitions}

Teacher Performance: $s$ and assess the teacher if your $d$ ERFORMANCE is or primo, good or, performance regular, poor or bad.

Optimum performance: 325 points

Good performance: 295 to 324 points

Regular performance: 196 to 294 points

Deficient performance: 161 to 195 points

Poor performance: less than 161 points

\section{Measuring instrument}

A questionnaire was drafted that must be answered by the resident doctors, which allows to give an account of the quality of the educational processes in the medical units that are the headquarters of the specialization courses in the State Delegation of the IMSS in Puebla, it has 65 closed questions directed to the activities carried out by the teacher in the classroom. Options to answer the questions are: always, more than half the time, approximately half times less than half the time, hardly ever. Your score is as follows:

Always: 5 points

More than half the time: 4 points

Approximately half of times: 3 points

Less than half the time: 2 points

Almost Never: 1 point

When answering the questionnaire, a measurement of the quality of the teaching performance will be obtained.

For its validation, a round of experts, two methodologies and two expert doctors in education were submitted for its content, determining the pertinence and consensus of the questions. The internal consistency will be evaluated with Cronbach's $\alpha$ coefficient.

\section{Collection of information}

After waiting for the authorization of CLIEIS No. s will request the doctors residing in the State Delegation of the IMSS in Puebla, their collaboration through a formal request through informed consent to answer the questionnaire. Once they accept to participate in it, residents will be asked to answer a questionnaire that will evaluate the performance of their teachers. The simultaneous application of the questionnaire will be sought in each training center for medical specialists. The capture of answers per question will be done in a blinded way regarding the teacher evaluated in Excel spreadsheets, one for each medical specialty venue and to be able to obtain the results for each specialty.

\section{Ethical aspects}

The present study fulfils the requirements of International Ethical Guidelines for Biomedical Research and Experimentation in Human Beings. ISBN 9290360569 of the Council of International Organizations of the Medical Sciences (CIOMS), 1993, Geneva, pp.53-56 and those cited in articles 100 in paragraphs I to VII and in article 101 of the General Law of Health in Mexico, updated in 2013. The study will be based on the basic principles of the declaration of Helsinki of the World Medical Association according to its modifications in Brazil of the year 2013. In the Regulation of the General Health Law of the United Mexican States in terms of experimentation in human beings, and in the Instructions for Operation of the Research Commission of the Mexican Institute of Social Security. This study complies with the rules and institutional instructions on scientific research; therefore, it will be carried out until it has been approved by the Local Research Committee of the IMSS. The Medical Professional Code of Ethics has the function of sensitizing the medical professional so that his professional practice unfolds in an area of honesty, legitimacy and morality, for the benefit of society, in accordance with the constitutional laws and standards that emanate from it.

In order to carry out this research, it is mandatory to have the informed consent and therefore with the written acceptance of the 
participation of the students, residents of the Puebla delegation, with detailed knowledge. Also, that it is your knowledge to be able to withdraw at the time you so choose. This research does not have conflict of interest in terms of 1 he results obtained, as it is to support allowing the re knowledge of acting teacher training to improve processes Delos. Basing quality assessment systems on the following elements: autonomy, independence, as well as the adaptation of procedures and methods of quality assessment to the profile and mission of the CIEFD. It does not represent any risk for the participants who agree to be part of the study, since it only consists of answering a validated questionnaire about the performance of the professors who give them class.

\section{Means}

Humans

a. Researcher at principal, professor of the Diploma of Teaching Professionalization for Health Education of CIEFD Puebla, professor of multiple online courses, coordinator of Diploma of Directors, teachers of teacher update in person. Postgraduate masters and doctorate in education. With experience in educational research.

\section{Materials}

a. Data collection sheets

b. Computer

Table 2 Gantt schedule

\section{Financing}

The own 1 a researcher to master, Table 1 expenses are considered.

Table I The own I a researcher to master, the following expenses are considered

\begin{tabular}{ll}
\hline Concept & Amount in Mexican pesos \\
\hline White sheets letter size & 500 \\
Transport & 500 \\
Pencils and pens & 100 \\
Total & 1100 \\
\hline
\end{tabular}

\section{Feasibility}

It is feasible, since it has the support of education coordinators to be able to apply the questionnaire. The expense is minimal and the researcher has experience in carrying out this type of research.

\section{Gantt schedule}

Table 2 shows Gantt Schedule

\begin{tabular}{|c|c|c|c|c|}
\hline Activities & June 2016 to January 2017 & Jan-17 & Feb-17 & Mar-17 \\
\hline \multicolumn{5}{|l|}{ Elaboration of the protocol } \\
\hline \multicolumn{5}{|c|}{ Registration and authorization of the protocol } \\
\hline \multicolumn{5}{|l|}{ Collection of information } \\
\hline \multicolumn{5}{|l|}{ Organization of information } \\
\hline \multicolumn{5}{|l|}{ Information analysis } \\
\hline \multicolumn{5}{|c|}{ Analysis and presentation of results } \\
\hline \multicolumn{5}{|c|}{ Preparation of preliminary document } \\
\hline Presentation of the final report & & & & \\
\hline
\end{tabular}

\section{Acknowledgments}

None.

\section{Conflicts of interest}

The author declares that there is no conflict of interest.

\section{References}

1. Martínez González A, Moreno Altamirano L, Ponce Rosas E, et al Teaching performance assessment in Public Health employing three different strategies. Gaceta Médica De México. 2011;147(3):234-243.

2. GJ-LJ Romero FE Rincón C. LH Jaime G. Teacher performance evaluation Chesterfield county public schools chesterfield, Virginia. 2008;168-178.

3. Román M, Murillo FJ. The Evaluation of Teaching Performance: Object of Dispute and Source of Opportunities in the Educational Field. Iberoamerican Magazine of Educational Evaluation. 2008;1(2):1-6.

4. Medina Revilla A, Dominguez Garrido MC, Ribeiro Gonçalves F. Training of university teachers in teaching skills. Magazine History of Latin American Education. 2011;17:119-138.
5. Santos MA. Sense and Purpose of the Evaluation of the University. Rev Perspectiva Educacional. UCV Institute of Education. 2001;37-38:9-33.

6. López Lasso MA, Solarte Benavides EJ. Evaluation by competences: an alternative for valuing university teaching performance. Journal of the Faculty of Economic and Administrative Sciences. 2013;14(1):216-257.

7. Chains MP, León AA. Teaching performance: Characteristics and methods to evaluate. ÁGORA Trujillo Venezuela. 2007;20:57-72.

8. Laura L Cánovas, Graciela Fasciolo. Evaluation of teaching performance Alte Brown No. 500. Chacras de Coria. Mendoza Argentina. M5528AHB. Rev FCA. 2004;14(1):69-78.

9. Estrada L. Teaching Performance. Department of Philosophy Faculty of Science of Education. University of Carabobo-Venezuela. 2001:1-38.

10. S/A Organization Manual of Regional Training Centers for Teachers in the area of health, finance and systems management. Unit of Organization and IMSS processes. 1996.

11. Luna Serrano E, Reyes Piñuelas E. Validation of the construction of a questionnaire for the evaluation of teaching competence. Electronic Journal of Educational Research. 2015;17(3):13-27. 
12. Tejedo FJ. Evaluation of the university teaching staff: methodological approach and some research contributions. Studies on Education, Navarra. 2009;16:79-102.

13. López Lasso MA, Solarte Benavides EJ. Evaluation by competences an alternative to assess university teaching performance. Journal of the Faculty of Economic and Administrative Sciences. 2013;14(1):216-257.

14. Sánchez Ochoa SA, Domínguez Espinosa A. Preparation of a bulleting instrument to evaluate teaching performance. Revista Mexicana de Investigación Educativa. 2008;13(37):625-648.

15. Martínez González A, Sierra Martínez 0, García Durán R, et al. Evaluation of teaching performance in the medical specialization courses of the Faculty of Medicine of the UNAM in the General Hospital Dr. Manuel Gea González. Elsevier México. 2012;1(1):14-21.

16. Martínez Chairez G, Guevara Araiza A. The evaluation of teaching performance. Ximhai. 2015

17. Pimienta Prieto JH. Development and validation of an instrument for measuring teacher performance based on competencies. REDU Journal of University Teaching. 2014;12(2):231-250.

18. Nava M \& Rueda M. Teacher evaluation in the public agenda. Electronic Journal of Educational Research. 2013;16(1);1-11.
19. Martínez-González A, Lifshitz Guinzberg A, Ponce-Rosas R, et al. Evaluation of teaching performance in medical specialization courses. Validation of an instrument. Medical Journal of the Mexican Social Security Institute. 2008;46(4):375-382.

20. RM Valley, Alaminos I, Contreras E, et al. Student questionnaire with basic medical science teaching. Medical Journal of the IMSS. 2004;42(5):405-411.

21. Reyes Piñuelas EP, Luna Serrano E. and Caso Niebla J. Psychometric properties of the Questionnaire for the Evaluation of Teaching Competence. Iberoamerican Magazine of Educational Evaluation. 2014;7(2):117-130.

22. Ramírez Munguía M, Cobos Aguilar H, Castillo Calderón J, et al. Scope of the strategy of the visit of teachers for teacher training. Medical Journal of the Mexican Institute of Social Security. 2006;44(4):297-302

23. Márquez Ibarra L, Madueño Serrano ML. Psychometric properties of an instrument to support the evaluation process of the university teacher. Electronic Journal of Educational Research. 2016;18(2):53-61.

24. García Garduño JM. What is the purpose of the evaluation of teaching? An exploratory study of the beliefs of the students. Education Policy Analysis Archives/Analytical. Archives of Educational Policies. 20142;21(15):20. 


\section{Annex I Informed consent letter}

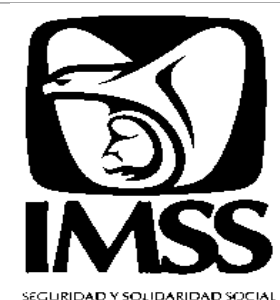

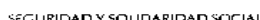

\section{MEXICAN SOCIAL SECURITY INSTITUTE \\ UNIT OF EDUCATION, RESEARCH \\ AND HEALTH POLICIES \\ HEALTH RESEARCH COORDINATION \\ INFORMED CONSENT LETTER}

Informed consent letter for participation in research protocols

Name of the study:

External Sponsor (if applicable):

Place and date:

Registry number:

Justification and objective of the study:

Procedures:

Possible risks and inconveniences:

Possible benefits you will receive when participating in the study:

Information about results and treatment alternatives:

Participation or withdrawal:

Privacy and confidentiality:

Teaching performance of medical specialty teachers, with and without teacher training, from the Puebla Delegation, of the 2016-2017 cycle.

Do not

Hospitals and clinics where Resident Physicians rotate January and February 2017

To know if in the Mexican Institute of the Social Security trainer of resident doctors, a competitive teaching act is fomented, where its performance is ideal so that the new generations of medical specialists are competent.

General Objective: To evaluate the teaching performance of medical specialty teachers, with and without teacher training, through their students, of the Puebla Delegation, in the academic year 2017.

Application of a questionnaire to be answered by resident doctors

Any

The results of this study will allow the recognition of teaching work and training in the teaching physicians that deserve it, in order to improve and achieve educational excellence.

The results will be informed to each teacher in a personalized way to improve the educational processes

You are informed that your participation is voluntary and can be withdrawn at any time

It is explained that your privacy and confidentiality of the information provided is respected

In case of collection of biological material (if applicable):

It does not authorize the taking of the sample.

If I authorize the sample to be taken only for this study.

If I authorize the sample to be taken for this study and future studies.

Availability of medical treatment in right holders (if applicable):

There will be medical treatment for damages caused to your body by the investigation

They will be informed at the end of the study about the results obtained from the investigation

Beverages at the end of the study:

In case of doubts or clarifications related to the study, you can contact:

Responsible Investigator:

Dr. María Urbelina Fernández Vázquez

Collaborators:

Name and signature of the subject

Witness 1

Name, address, relationship and signature
Dr. María Urbelina Fernández Vázquez

(Family Doctor, Professor of CIEFD)

Name and signature of the person who obtains the consent

Witness 2

Name, address, relationship and signature

This format is a guide that must be completed according to the characteristics of each research protocol, without omitting relevant information from the study.

Code: 2810-009-013 


\section{Annex 2 Questionnaire}

This questionnaire seeks to know how educational activities are carried out in the specialization course that you carry out within the Mexican Institute of Social Security that is why we ask for your valuable collaboration, answering the following questions.

Teacher's name

Subject matter given by the teacher

Of the specialty

Date on which this questionnaire answers

The sex of the person who answers this questionnaire is

Your year of residence is

There are no correct or incorrect answers, we only ask you to send them honestly. To do this you must always keep in mind the teacher who is most of the time with the group of residents in the last 6 months. Place an $\mathrm{X}$ inside the cell that corresponds to your assessment of the performance described.

\section{The teacher in the last 6 months:}

\begin{tabular}{|c|c|c|c|}
\hline \multirow[t]{2}{*}{ Dimensions } & \multicolumn{3}{|l|}{ Evaluation criteria } \\
\hline & More than half the time & Less than half the time & Hardly ever \\
\hline \multirow[t]{12}{*}{$\begin{array}{l}\text { General information on the } \\
\text { acting teacher }\end{array}$} & Start with academic activities & & \\
\hline & It is careful (a) in their personal appearance & & \\
\hline & Attend class according to the specialization program & & \\
\hline & He is punctual in his entrance and exit of class & & \\
\hline & Say hello when you start the class & & \\
\hline & Encourages good interpersonal relationships teacher-student, alum non-s & dent & \\
\hline & Shows interest in the opinions of the whole group in class without impos & $\mathrm{g}$ their judgment & \\
\hline & He is respectful to us & & \\
\hline & It favors a cordial atmosphere & & \\
\hline & He is a guide in the development of my learning. & & \\
\hline & Review the academic papers requested & & \\
\hline & Establish good relationship with students & & \\
\hline \multirow[t]{17}{*}{ Development of the class } & Unveils the program of the course & & \\
\hline & Address the doubts that arise in the class session & & \\
\hline & Give clear and precise explanations on the topic that is developed & & \\
\hline & Facilitates an active practice in all students & & \\
\hline & Solve any educational problems that arise in the classroom & & \\
\hline & Achieves that the pair students actively in class ticipen & & \\
\hline & Check our understanding of the educational session & & \\
\hline & Promotes collaborative work in class & & \\
\hline & It exposes updated information on the subject & & \\
\hline & Uses support materials for the class to benefit teaching & & \\
\hline & Motivate students to attend classes & & \\
\hline & He has mastery of his subject & & \\
\hline & Offers advice and support & & \\
\hline & Use technological resources & & \\
\hline & I am satisfied with my learning achieved thanks to the work of teaching & It have in this subject & \\
\hline & Promotes the critical respectful & & \\
\hline & Accepts opinions different from yours, without harmful repercussions & & \\
\hline
\end{tabular}


Table Continued....

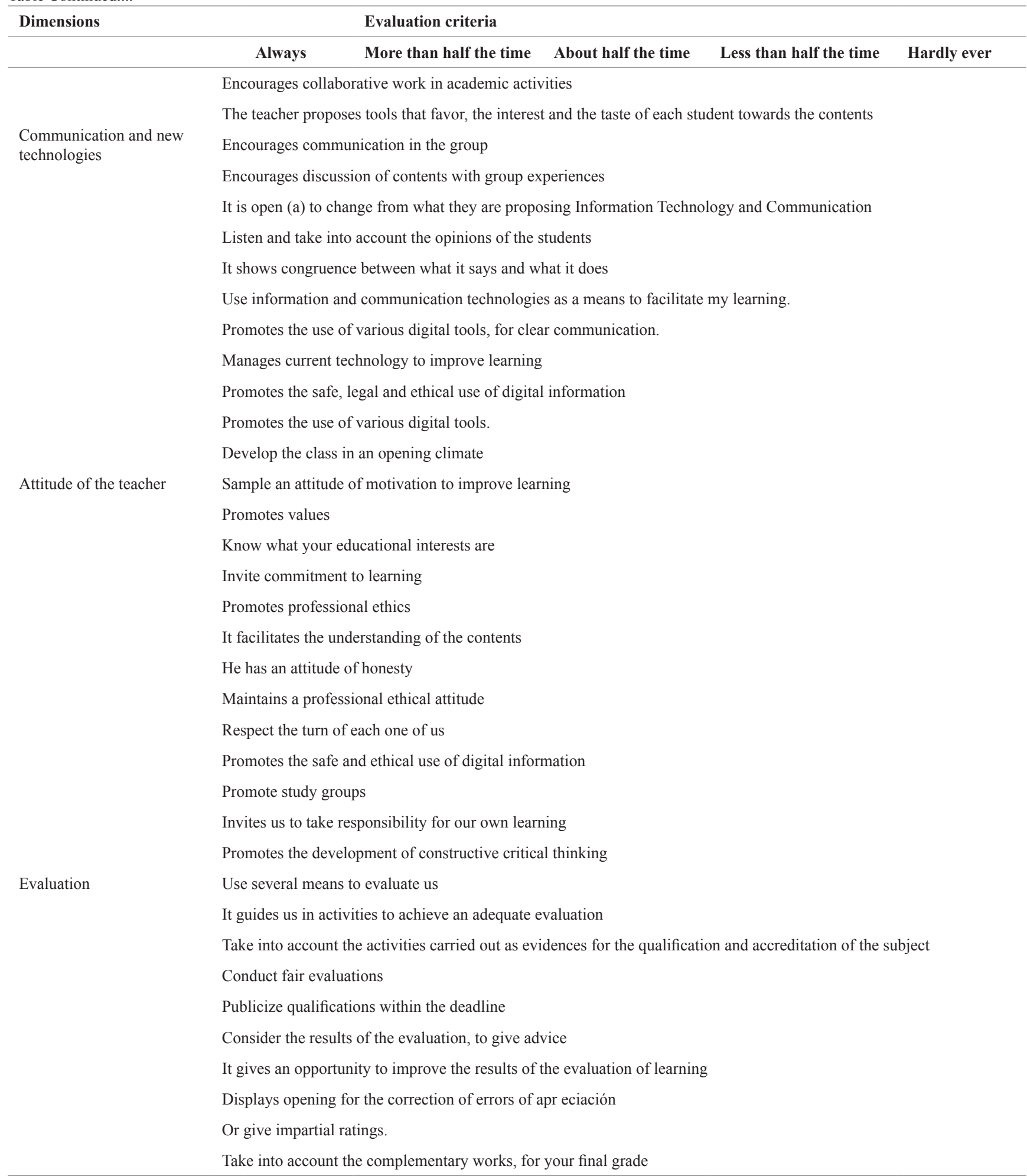

